\title{
Strategi Penguatan Kreativitas Seniman Ketoprak DIY dari Tahun 1999 hingga Tahun 2009
}

\section{\& THEATREREVIEW}

jurnal tari, teater, dan wayang

volume 2 number 2 ,

November 2019

page $94-105$

\author{
Yudiaryani $^{1}$, Wahid Nurcahyono, dan Silvia Anggreni Purba \\ Program Studi Teater, Fakultas Seni Pertunjukan, Institut Seni Indonesia \\ Yogyakarta
}

\begin{abstract}
Cultural identity in ketoprak performance should depart from all cultural products themselves. Strengthening the form of ketoprak performance in the middle of the era becomes important for artists in building their creativity. The strategy was designed so that people assume that ketoprak was theirs and able to be their representation. Based on the data collected, the number of groups, performances, and ketoprak artists in DIY were as follows. The number of groups in four districts and one municipality were 497 groups. The number of ketoprak showed from 1999-2009 was 145 times. The highest number of ketoprak groups was in Kulonprogo Regency, followed by Gunungkidul Regency, Bantul Regency, Sleman Regency, and finally the Municipality. The year 2005 was a milestone in the development of ketoprak to the present. The successful renewal of ketoprak shows can be seen by the number of shows which are 113 times over five years (from 2005 to 2009), which means that there were twenty ketoprak shows every year, and every month there were two ketoprak shows. The condition was triggered by several factors as follows. First, local government awareness to determined the icon of DIY tourism as part of globalization. Second, the awareness of artists to package performances that match the demands of the times. Third, awareness of the artistic layout strategy using symbolic and supported by Tobong ketoprak tricks. Fourthly, the influence of ketoprak humor and ketoprak R\&D which still uses the style of play and jokes, causes the ketoprak show to be no longer a mere political tool, but a tool and place of friendship for the citizens. Fifth, the story was no longer based on myths, chronicles and legends, but penetrated the wayang story but with a more contextual interpretation of the story with the present. By seeing the many activities of ketoprak performances in DIY it can be said if ketoprak has become an icon of culture and tourism in DIY. Ketoprak performances tread its survival was no longer a traditional art, but has become a form of modernist art. Over the past ten years, the ketoprak show has experienced quite improved conditions. The vigilance of artists and audiences must be constantly reminded. The trick was to continuing to enhance the role of government as a protector of arts and culture. The ketoprak festival must continuing to be held continuously. Improving the skills of ketoprak artists must continuing to be sharpened. Of course the friendship between Ketoprak artists must continuing to be encouraged. Government's appreciation for ketoprak artists must be increased.
\end{abstract}

Keywords: identity; ketoprak; strengthening; globalization

1 Alamat korespondensi: Institut Seni Indonesia Yogyakarta, Jl. Parangtritis Km. 6,5 Yogyakarta. E-mail: yudi_ ninik@yahoo.co.id; HP: 081227085556 


\section{Pendahuluan}

Sektor industri kreatif di bidang seni pertunjukan memiliki potensi untuk dikembangkan dengan hasil karya kreatif seniman Indonesia dapat disejajarkan dengan bangsa lainnya di dunia. Hal ini terbukti dengan banyak karya seniman seni pertunjukan Indonesia diakui di komunitas internasional seperti karya tari Jawa, wayang kulit, musik tradisional. Bagi seni pertunjukan, karakter industri kreatif ditentukan sebagian besar lewat input tenaga kerjanya berupa sumber daya manusia kreatif yang berbasis pada intelektualitas.

Penelitian ketoprak (Jawa: kethoprak) dari tahun 1999-2009 ini berlandaskan pada tiga permasalahan pokok, yaitu: pertama, cara mengidentifikasi pertunjukan ketoprak sebagai bentuk pewarisan dan pelestarian seni dan budaya masyarakat DIY. Kedua, cara mengidentifikasi peranan ketoprak di tengah upaya pembinaan kesenian di DIY. Ketiga, cara mengidentifikasi pertunjukan ketoprak terkait dengan perubahan kreativitas seniman ketoprak. Tujuan penelitian ini adalah pertama, menganalisis kreativitas para seniman ketoprak. Kedua, menganalisis upaya pemerintah daerah melindungi keberadaan pertunjukan ketoprak di DIY. Ketiga, menganalisis apresiasi penonton terhadap pertunjukan ketoprak. Manfaat penelitian ini adalah pertama, menemukan strategi atau cara-cara yang ditempuh seniman agar tetap berkarya di bidangnya. Kedua, menemukan strategi atau cara-cara yang ditempuh pemerintah daerah dalam upaya melestarikan pertunjukan ketoprak.

Pewarisan dan pelestarian ketoprak sebagai aset budaya merupakan suatu penopang ruang lingkup pembangunan nasional secara menyeluruh. Di satu pihak pembangunan dan perubahan keadaan seringkali mengubah keadaan yang ada. Kemajuan yang dicapai menumbuhkan kekhawatiran dan keprihatinan terhadap rusaknya warisan budaya dan aset-aset kebudayaan. Dalam hal ini, masyarakat wajib menjaga dan mempertahankannya dari segala gangguan dan bahaya yang mengancam. Amanat warisan budaya hendaknya terus diemban dengan segala usaha pelestarian dan pemanfaatan yang aktif positif karena sarat dengan nilai-nilai filosofi, etika, dan pesan moral yang harus dipelihara dan dikembangkan demi kepentingan manusia secara menyeluruh dan utuh.

Ketoprak adalah sejenis seni pertunjukan teater berasal dari Jawa. Dalam sebuah pertunjukan ketoprak, cerita dramatik diselingi dengan lagu-lagu Jawa dan diiringi dengan gamelan. Tema cerita dalam sebuah pertunjukan ketoprak bermacam-macam. Tema biasanya diambil dari cerita legenda atau sejarah Jawa, tetapi banyak pula tema yang diambil cerita dari luar negeri. Namun tema cerita tidak pernah diambil dari repertoar cerita epos Ramayana dan Mahabharata. Epos tersebut menghasilkan pertunjukan wayang wong (orang), bukan pertunjukan ketoprak.

Ketoprak sebagai kesenian rakyat tradisional mampu berkembang seiring perkembangan zaman dan teknologi karena ketoprak memang lentur, luwes dan adaptif. Bahkan ketoprak selalu terbuka terhadap pengaruh konsep seni dari luar ketoprak. Hal itu terlihat jelas dari sejarah perkembangan ketoprak yang terus berkembang, yaitu mulai dari ketoprak lesung, ketoprak ongkek, ketoprak pendapan, sampai ketoprak panggung (tobong). Dalam kaitan teknologi komunikasi, ketoprak juga bisa beradaptasi dengan teknologi audio, sehingga mulai 1937/1938, ketoprak sudah mengudara lewat radio (RRI) Yogyakarta, yang dipelopori grup Ketoprak Krido Raharjo pimpinan Ki Cokrojiyo. Mulai 1972, ketoprak juga bisa tampil secara audio-visual lewat TVRI.

Kebudayaan Jawa terus mengalami pergeseran. Idiom-idiom yang merupakan ajaran luhur sekarang mengalami perubahan sehingga muncul idiom-idiom yang merupakan kebalikan ungkapan yang berlaku di masa lalu. Misalnya sepi ing pamrih rame ing gawe berubah menjadi sepi gawe rame ing pamrih; becik ketitik ala ketara menjadi becik kesirik ala ketrima; wani ngalah dhuwur wekasane menjadi wani ngalah dhuwur rekasane. Setiap 
kebudayaan senantiasa berubah secara radikal (mendalam, menyeluruh) inkremental (bertahap, pelan-pelan,tambalsulam), evolusif, revolusif, bahkan bisa berubah arah atau berbalik total. Hal itu sudah diramalkan oleh pujangga besar Ranggawarsita. Ranggawarsita meramal bahwa suatu saat wong Jawa kari separo karena karakteristik budaya Jawa yang selalu terbuka. Oleh karena itu, hal yang mungkin terjadi bahwa budaya tradisional yang berlaku dalam seni tradisi maupun masyarakat Jawa saat ini memang tinggal separuh. Selebihnya, kebudayaan tersebut sudah terpengaruh budaya asing. Demikian juga kesenian adiluhung ketoprak mengalami banyak perubahan terutama setelah lahir konsep ketoprak garapan, ketoprak humor dan ketoprak ringkes. Dengan demikian, nilai-nilai budaya adiluhung yang tinggal separuh itu perlu dijaga dari kepunahan. Keberadaannya sangat tergantung dengan sikap para tokoh dan pelaku ketoprak di Yogyakarta, serta pemerintah daerah sebagai fasilitator pelestarian dan pengembangan kesenian ketoprak.

Kajian seni pertunjukan berada dalam bentangan produksi makna oleh seniman dan komunikasi pesan bagi penonton. Marco de Marinis menyatakan bahwa produksi dan komunikasi antara seniman dan penonton menuntut sistem dan metode kerja yang tidak saling tergantung tetapi saling melengkapi, misalnya naskah drama membutuhkan konteks di saat pemanggungannya serta kehadirannya menggantungkan tubuh aktor dan artistik panggung lainnya. Demikian juga naskah drama membutuhkan unit-unit linguistik yang menjadi transkrip potensial bagi linguistik panggung (1993: 10).

Proses kerja interteks Julia Kristeva menempatkan teori jaringan teks Roland Barthes sama dengan gagasan analisis tekstual pertunjukan Marinis. Teori jaringan menjadi suatu metode yang digunakan untuk memaknai pertunjukan teater modern dan kontemporer. Pemilihan suatu objek pembacaan seperti bentuk peristiwa teater melibatkan pilihanpilihan elemen pertunjukan teatrikal. Teater memiliki peralatan khas bagi pemindahan suatu budaya sumber pada penonton target, yaitu melalui konteks teatrikal. Interteks di dalam pertunjukan teater merupakan praktik pembacaan teatrikal (Barthes, 1981: 31). Patrice Pavis menyatakan bahwa pertunjukan teatrikal memiliki peralatan transmisi yang tidak dimiliki media lain untuk berkomunikasi. Peralatan transmisi tersebut adalah elemenelemen teatrikal yang terdiri dari pemeranan, penulisan naskah, penyutradaraan, penataan artistik dan audio visual, pengelolaan produksi, dan pemenuhan akan kehadiran penonton (1992: 119).

Penelitian ini dilaksanakan dengan metode gabungan antara penelitian kepustakaan, wawancara, dan analisis. Sesuai dengan karakteristik objek penelitian dan teori yang digunakan, penelitian ini menggunakan metode penelitian kualitatif naturalistik. Metode kualitatif adalah metode untuk mencari makna di balik data, sedangkan metode naturalistik adalah membangun kerangka pemikiran, filsafat, dan operasionalisasi metodologis. Teknik analisis dilakukan secara interpretatif dan menyeluruh. Teknik ini dilakukan dalam rangka mencari esensi dan mengimplisitkannya dalam observasi, analisis, serta pembuatan kesimpulan (Muhajir, 2000: 79).

\section{Pembahasan}

Acara Pertemuan Seniman Ketoprak DIY tahun 1972 yang diselenggarakan oleh Taman Budaya Yogyakarta menghasilkan rumusan bahwa ketoprak sebagai kesenian (drama/ teater) rakyat yang tumbuh subur di wilayah Yogyakarta, Jawa Tengah, dan Jawa Timur, terbagi dalam tiga periodisasi, yaitu: Periode Ketoprak Lesung (1908-1925), Periode Ketoprak Peralihan (1925-1948), dan Periode Ketoprak Gamelan (mulai 1948-1990). Kemudian di acara Lokakarya Ketoprak yang diselenggarakan Taman Budaya Yogyakarta di tahun 1997 memunculkan gagasan bentuk baru ketoprak, yakni: Ketoprak Garapan. Dengan demikian, mulai saat itu dikenal adanya Ketoprak Konvensional dan Pembaruan (1908-1997) serta Ketoprak Garapan (1999- 
2009). Adapun menurut Kussudyarna (1989: 15-18) periodisasi ketoprak sebagai berikut.

\section{a. Periode Ketoprak Lesung}

Tahun 1908-1925, embrio ketoprak lesung adalah permainan para petani yang biasanya dilakukan pada malam hari pada saat-saat terang bulan. Bentuk ketoprak periode ini menggunakan tetabuhan pokok yang disebut lesung, yaitu: alat menumbuk padi yang terbuat dari kayu nangka atau jati. Dalam perkembangannya, ada yang kemudian menambahkan alat-alat bunyi lain, seperti potongan-potongan bambu kecil yang disebut kotekan. Mereka bermain di halaman rumah, berdendang dengan iringan bunyi lesung yang dipukuli. Permainan ini disebut gejog. Lagu dan susunan syairnya sangat sederhana. Kemudian permainan itu dikembangkan dengan beberapa penyanyi yang tampil di arena dengan menari dan membawa cerita tentang kehidupan para petani sehari-hari. Dialog peran menggunakan bahasa Jawa sehari-hari yang dipergunakan di pedesaan. Bentuk dialog yang dilakukan ada dua macam, yaitu: tembang dan gancaran. Sistem penyampaian dialog dilakukan dengan improvisasi.

Bentuk tarian dari permainan ketoprak ini juga sederhana sekali. Tangan kiri dan tangan kanan penari mengepal. Lengan kanan ditarik ke depan dan kemudian ditarik ke belakang. Hal itu dilakukan secara bergantian dengan tangan dan lengan kiri. Langkah kaki bergerak seperti orang berjalan biasa, tetapi ritmis. Mereka bermain menghadap penonton yang mengerumuni dari empat arah, yaitu: depan, belakang, kanan, dan kiri. Instrumen lesung dan musisinya berada di belakang mereka yang bermain peran. Pakaian yang dikenakan sangat sederhana, yaitu: pakaian ragam Jawa yang biasa dipakai petani sehari-hari tanpa rias.

\section{b. Periode Ketoprak Peralihan atau Ketoprak Gamelan}

Tahun 1925-1948, ketoprak tumbuh dengan ciri-ciri sebagai berikut. Pada periode ini, ketoprak beralih dari tetabuhan lesung ke tetabuhan campur, yaitu: alat musik yang digunakan sudah bertambah dengan rebana dan biola. Lagu yang digunakan seperti pucung, dan mijil. Ketoprak masih menggunakan tari, tembang, cerita, pakaian, dan rias sederhana. Selain menggunakan pakaian Jawa, juga digunakan busana ketoprak yang sering disebut stambulan atau mesiran. Pementasannya semakin atraktif dan masih bertujuan sebagai hiburan.

Pada tahun 1929, berdiri perkumpulan Ketoprak Krido Mudo yang kemudian terkenal dengan nama Ketoprak Kertonaden di Yogyakarta. Perkumpulan ini berasal dari kampung Cokrodiningratan, Yogyakarta, dipimpin Mangunsardjono dengan dalang Ki Pawirosono, bekas pemain wayang orang Surakarta. Hasil wawancara dengan seniman-seniman ketoprak angkatan tua menegaskan bahwa Krido Mudo inilah yang pertama kali menggunakan panggung darurat atau di kalangan ketoprak disebut tobong. Kerangka bangunan dan dinding panggung semuanya dari bambu, sedangkan atap berupa welit atau daun tebu yang dikeringkan. Unsur tari juga ditinggalkan, tetapi peran wanita masih dilakukan oleh pria. Bahkan Krido Mudo melengkapi pertunjukannya dengan dekor layar dengan berbagai lukisannya. Lakon-lakon yang ditampilkan tidak hanya berasal dari cerita-cerita rakyat, tetapi mulai disajikan juga lakon-lakon yang diambil dari babad, sejarah, dan cerita-cerita popular lainnya.

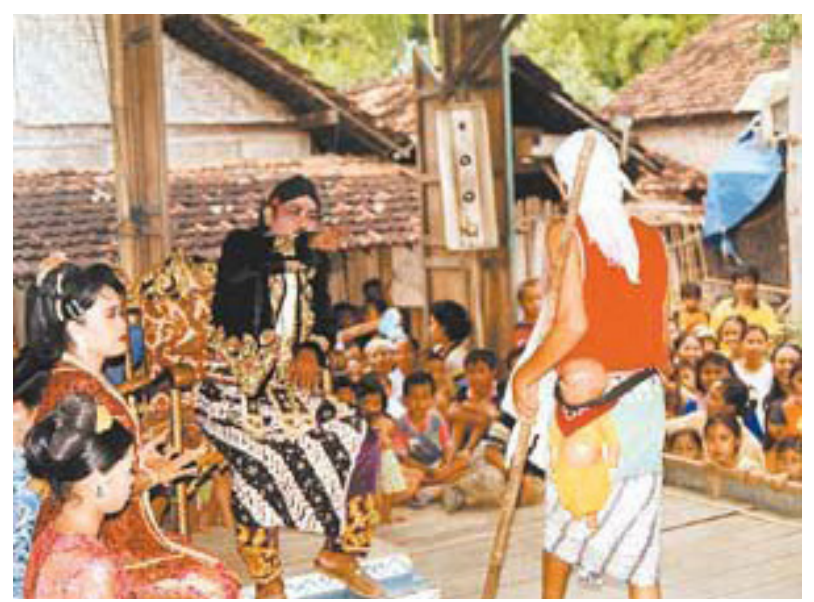

Gambar 1. Bentuk pertunjukan ketoprak lesung yang diproduksi ulang. 
Pada tahun 1931, berdiri rombongan ketoprak profesional lagi pimpinan Sosroganjur dengan dalang dari Kampung Dagen, Yogyakarta. Sebelumnya, Sosroganjur memimpin rombongan Ande-ande Lumut dan wayang orang. Rombongan ketoprak inilah yang pertama kali menggunakan pemain wanita. Pada awal tahun 1932, grup Ketoprak Mardi Wandowo yang dipimpin Somosilam dengan dalang Pawirobuwang dan Atmosuripto didirikan. Beberapa orang dari pemain Mardi Wandowo berasal dari Krido Mudo. Untuk pertama kali, Mardi Wandowo pentas di Wetan Benteng, kemudian dilanjutkan ke Purworejo, keliling ke arah barat. Hingga tahun 1937, Mardi Wandowo mengadakan pertunjukan di Jakarta.

Antara tahun 1937 sampai 1948, di Yogyakarta terdapat beberapa grup ketoprak keliling yang berbeda bentuknya dengan ketoprak keliling sebelumnya. Ketoprak keliling ini dinamakan Ketoprak Ongkek atau Ketoprak Ketan yang berpentas keliling kampung-kampung dan desa-desa. Tempat pementasan biasanya diselenggarakan di halaman rumah penduduk. Untuk penerangan di setiap pentas digunakan obor. Jumlah pemain berkisar 6-10 orang dan pemain yang tidak mendapatkan giliran untuk memainkan peran bertugas sebagai penabuh gamelan dari besi yang umumnya bernada slendro. Gamelan ini disebut gamelan barut.

\section{c. Periode Ketoprak Pembaruan}

Periode ini berlangsung dari tahun 1948-1990. Pada tahun 1948, sesudah
Ketoprak Mataram Krido Raharjo lebih sepuluh tahun bermain di radio tampak ada usaha memperbarui ketoprak. Untuk memenuhi kepentingan siaran di radio yang bersifat auditif itu, Krido Raharjo yang akhirnya resmi menjadi Ketoprak Mataram RRI Yogyakarta cenderung menggunakan naskah dan dialog. Penggarapan sebagai pembaruan itu berkaitan dengan ekspresi lewat suara dan pemanjangan dialog dengan penekanan pada isi serta permainan bahasa. Begitu pula gendinggending pengiringnya dilengkapi dengan sound effect. Percobaan pertunjukan di pangggung dengan lakon dari negeri asing, seperti Hamlet juga diselenggarakan Ketoprak Mataram RRI Yogyakarta dengan sutradara Soemardjono. Dalam percobaan ini, sutradara ingin memberi warna baru ketoprak dengan cerita utuh.

Pada tahun 1964, Ketoprak Mataram Krido Mardi membuat eksperimen pentas ketoprak dengan lakon Rara Mendut yang bertempat di Sasono Hinggil Dwi Abad. Eksperimen ini dimaksudkan sebagai usaha pembaruan dan peremajaan pemain. Sesungguhnya yang menonjol dalam pertunjukan ini berada dalam dua wilayah garap karya, yaitu: wilayah penggarapan pemain muda dalam rangka kaderisasi, dan wilayah permainan gending-gending yang difungsikan sebagai ilustrasi. Sementara itu, ketoprak gaya baru, Siswo Budoyo, dari Tulungagung menekankan masalah penataan panggung yang menyangkut dekorasi, teknik perlampuan dan permainan properti yang menakjubkan

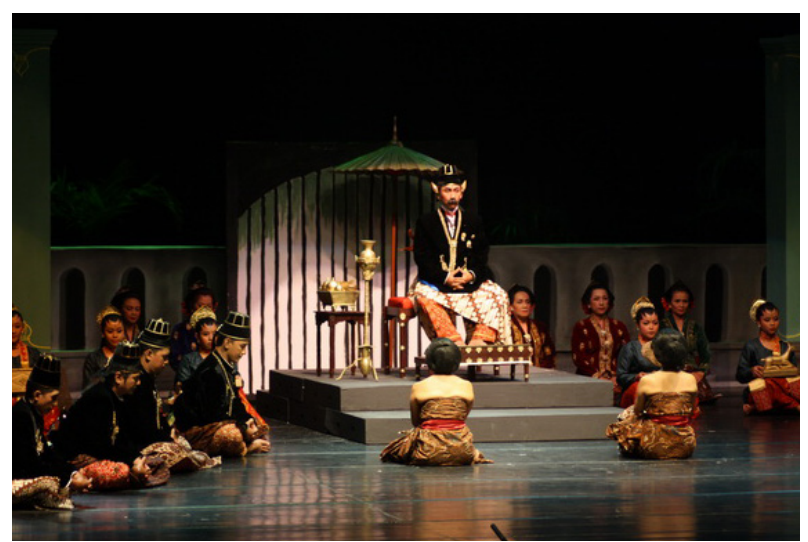

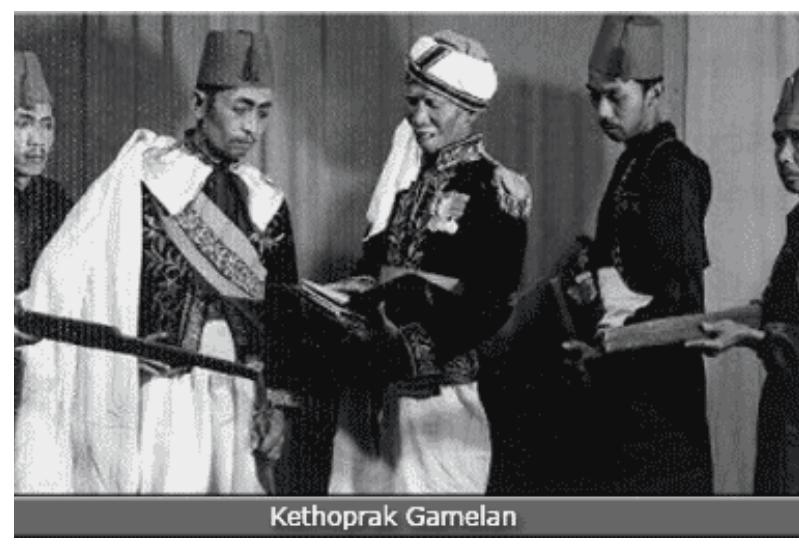

Gambar 2. Bentuk pertunjukan Ketoprak konvensional: Ketoprak Gamelan. 
penonton. Sapta Mandala meningkatkan kesadaran terhadap nilai profesionalisme dalam arti sesungguhnya, yaitu: dedikasi kepada profesi yang bermakna tanggung jawab kepada karya, kreativitas, disiplin, dan menghilangkan tradisi seni ketoprak yang sudah tidak selaras dengan zaman.

Usaha pembaruan tersebut ternyata banyak mempengaruhi pertumbuhan dan perkembangan ketoprak sampai tahun 1990-an. Pola sajian ketoprak dan beberapa variasinya, baik RRI, radio swasta niaga, maupun televisi, terpengaruh oleh pertunjukan Ketoprak Sapta Mandala. Begitu pula grup-grup ketoprak amatir tingkat kecamatan di Daerah Istimewa Yogyakarta yang tiap tahun ikut serta dalam festival ketoprak yang diselenggarakan secara bersama antara Bidang Kesenian Kanwil Depdikbud, Inspeksi Kebudayaan Dinas P dan K Propinsi Daerah Istimewa Yogyakarta, Taman Budaya Ditjen Kebudayaan Depdikbud, BKKNI (Badan Koordinasi Kesenian Nasional Indonesia) Pemerintah Dearah Tingkat II Kabupaten Bantul, Kulonprogo, Gunung Kidul, Sleman dan Kotamadya Yogyakarta memiliki pola sajian yang tidak berbeda jauh dengan pola pertunjukan kelompok tersebut.

Jika dilihat dari sudut keativitas, hal tersebut tidak menguntungkan. Sekarang lakon ketoprak banyak ditulis dalam sistem naskah utuh, sehingga permainan spontanitas banyak berkurang. Dari naskah lakon dengan sistem penulisan naskah utuh, warna sajian ketoprak telah terpola

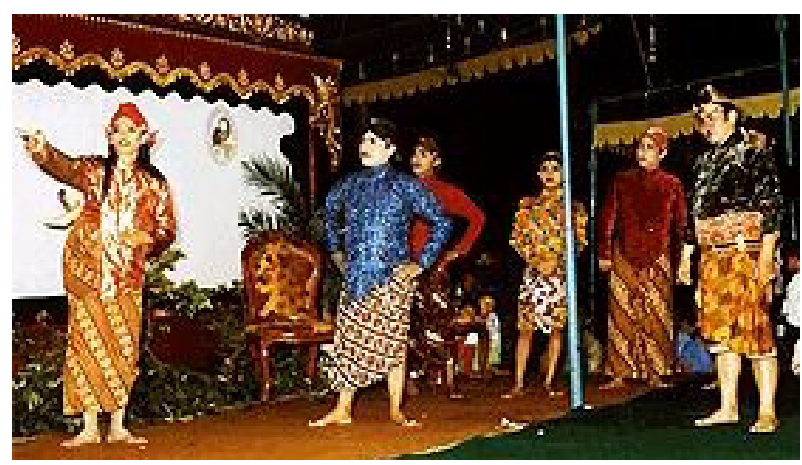

Gambar 3. Pementasan Ketoprak Eksekutif Legislatif (eksel) yang dimainkan di Taman Budaya Yogyakarta (TBY) Selasa (23/12/2008). Ketoprak dengan lakon Wahyu Keprabon. meskipun sesungguhnya sutradara dapat membuat pola sajian lain berdasarkan konsepnya. Kenyataannya, grup-grup ketoprak amatir, terutama yang dilakukan anak-anak muda dan untuk sajian di televisi, sukar melepaskan pengaruh naskah utuh. Oleh karena itu, sejak awal berdirinya, Sapta Mandala sudah menyiapkan naskahnaskah lakon ketoprak, baik yang utuh maupun yang ditulis secara garis besar. Penulisan lakon-lakon ketoprak itu tidak hanya dimaksudkan untuk memberikan kemudahan bagi anak-anak muda da-lam olah ketoprak, tetapi juga untuk memberikan kemungkinan perkembangan ketoprak lebih lanjut. Selain itu, penulisan tersebut dapat menjadi dokumentasi lakonlakon ketoprak.

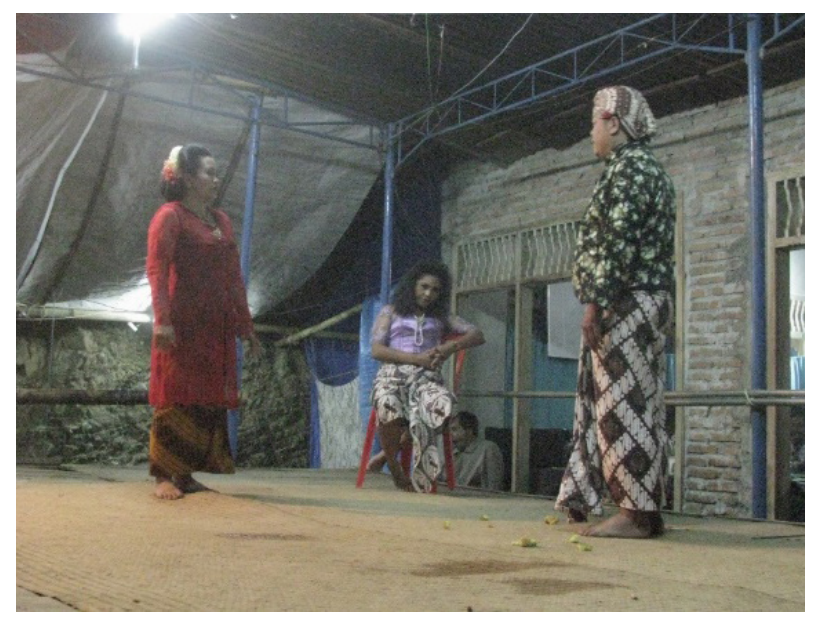

Gambar 4. Ketoprak Ngesti Budaya. Kulonprogo. Lambangsari Ngedan 2009. Pertunjukan Ketoprak ini ditampilkan di halaman rumah penduduk yang memiliki hajat mantu.

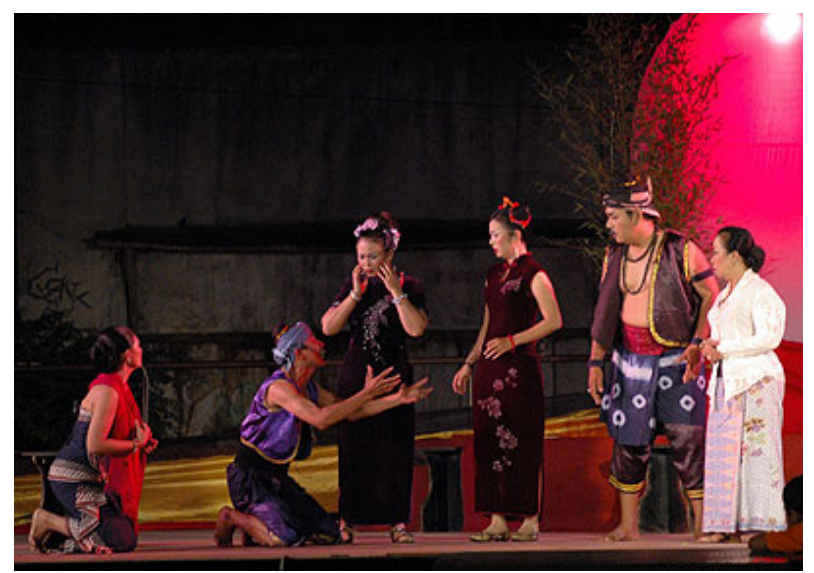

Gambar 5. Pementasan Putri Cina berdasarkan novel karya Sindhunata dalam rangka 100 tahun Kebangkitan Nasional di Kapal Cheng Ho, Komplek Klenteng Tay Kak Sie, Semarang 24 Mei 2008. 


\section{d. Periode Ketoprak Humor dan Ketoprak Ringkes}

Periode ini berlangsung dari tahun 1999-2009. Acara Panasonic Awards 2000 yang ditayangkan stasiun televisi RCTI memberi penghargaan bagi ketoprak humor sebagai acara favorit pilihan pemirsa. Sebelum tampil di layar kaca dalam bentuk baru, kelompok ketoprak humor tersebut merupakan gobyok campursari yang ada di Taman Mini Indonesia Indah. Berawal dari bubarnya Srimulat, Timbul dan kawan-kawan kemudian mendirikan Yayasan Samiaji yang melahirkan Ketoprak Humor Samiaji. Srimulat pernah membuat ketoprak yang sesuai dengan pakem tradisi, tetapi tidak laku. Karena tidak laku, Srimulat kemudian membuat ketoprak humor. Meski penuh improvisasi, tetapi ketoprak humor tidak memelesetkan jalan ceritanya. Cerita-cerita sejarah dan legenda yang ditampilkan diambil dari berbagai macam buku dan legenda yang memang sudah ada. Kemudian skenario dibuat dengan pengembangan. Upaya revitalisasi tersebut ternyata membawa hasil dengan banyaknya perhatian penonton. Pertunjukan ketoprak humor menghadirkan pula wajah-wajah terkenal, seperti: Pak Bendot, Tessy, Timbul, Tarsan, Eko, Nurbuat, Topan, dan Lesus.

Penggarapan ketoprak humor mengendorkan dramaturgi ketoprak sebagai sebuah teater rakyat yang digemari di Jawa Tengah dan Jawa Timur. Bahkan pemain ketoprak humor bisa lupa tokoh yang sedang diperankannya. Pemain

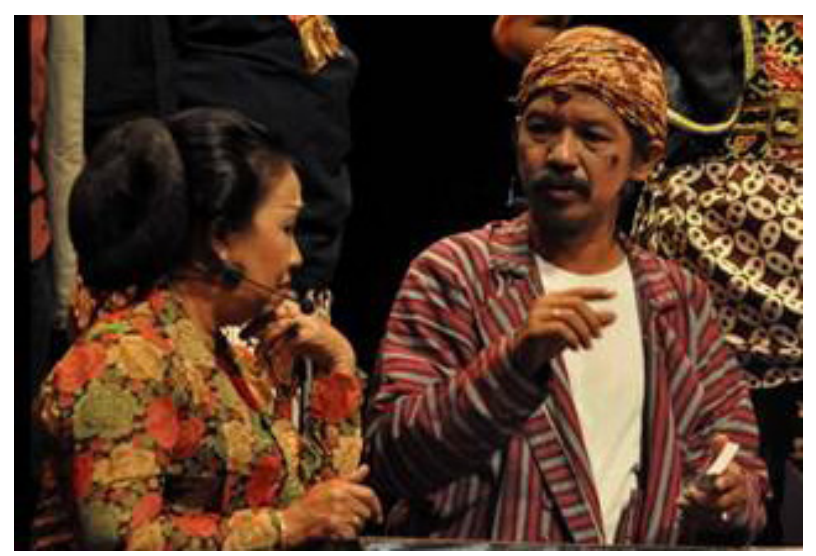

seperti Tarsan punya resep sendiri. Ia selalu membawa kertas contekan yang diselipkan di dalam stagen untuk mengingat tokoh yang dibawakannya. Sebagian pemain tetap mengangkat karakter permainan panggungnya sendiri yang telah dikenal publik seperti gaya bloon khas Pak Bendot, gaya genit yang menjadi trademark Tessy yang jemarinya dipenuhi cincin-cincin bermata besar. Pendeknya, dengan ciri khas masing-masing, seluruh awak ketoprak humor berupaya untuk menghidupkan cerita yang dilakonkan. Kekhasan tersebut menyebabkan ketoprak humor digemari. Di sisi lain, ketoprak humor tetap memiliki dramaturgi dengan jenis pertunjukan yang kental dengan humor sebagai elemen yang mudah diapresiasi.

Pada tanggal 20 September 2005 di Bentara Budaya Yogyakarta digelar pertunjukan ketoprak berjudul Minggat. Lebih dari 400 penonton dari berbagai kalangan, antara lain: seniman, intelektual, sampai tukang becak, menikmati pertunjukan tersebut di kursi atau tikar maupun berdiri di sepanjang jalan yang terletak di depan panggung pertunjukan. Di panggung yang dibangun dari papan keropos dan ditutup lembaran plastik, mereka melihat seorang raja yang bermahkota dan berbusana serba gemerlap sedang termangu. Dibalut dengan humor yang khas-kebanyakan berlangsung dalam bahasa Jawa-pertunjukan yang berlangsung sekitar dua jam ini sungguh menghibur sekaligus mengajak penonton

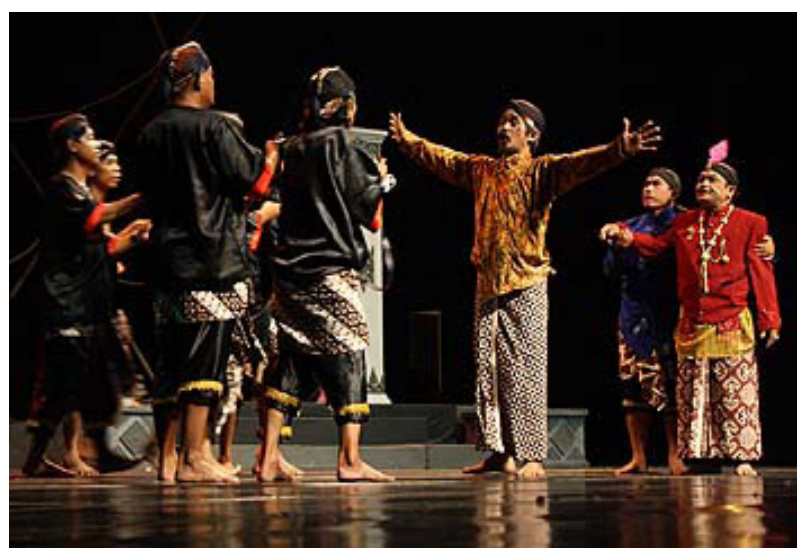

Gambar 6. Pentas Ketoprak Ringkes Tjap Tjonthong pada Sabtu-Minggu, 4-5 Mei 2013 Sapa Ngedan Keduman di Concert Hall Taman Budaya Yogyakarta (TBY). 
untuk merenungi situasi sosial politik sezaman.

Pementasan ini boleh dianggap sebagai cermin kegiatan seni rakyat yang tidak juga mau mati. Teater rakyat yang praktis tinggal menjalani masa-masa akhir hayatnya ini pernah berubah bentuk dari bentuk formal sebagai milik penguasa menjadi penyampai kelucuan melalui ketoprak humor di televisi. Kini, beberapa penggiatnya, yaitu: Marwoto, Den Baguse Ngarso, Nano Asmorodono, Yu Beruk, serta Sundari, merintis bentuk yang lebih luwes yang disebut ketoprak ringkes.

Mereka memang membuat ketoprak menjadi serba ringkas termasuk jumlah aktor panggung maupun pemain musik. Jumlah aktor itu berkaitan erat dengan kemampuan pemilihan sudut pandang cerita, penyusunan naskah yang lebih rinci dan padat, penyuntingan adegan. Mereka mempertahankan tokoh-tokoh cerita di dalam kerajaan, namun memutarbalikkan posisinya dan memilih rakyat sebagai hero. Mereka membuang segala macam ornamentasi yang pernah menjadi kejayaan ketoprak dengan membiarkan panggung kosong dan sangat bersahaja. Mereka berusaha untuk menghidupkan segala hal yang ada di panggung dengan kekuatan imajinasi. Ketoprak ringkes memperbarui musik dengan hanya menggunakan kendang, rebana, gong, violin, dan keyboard. Mereka mengutamakan unsur komunikasi yang terjalin erat lewat humor yang menjadi daya tarik utama di samping

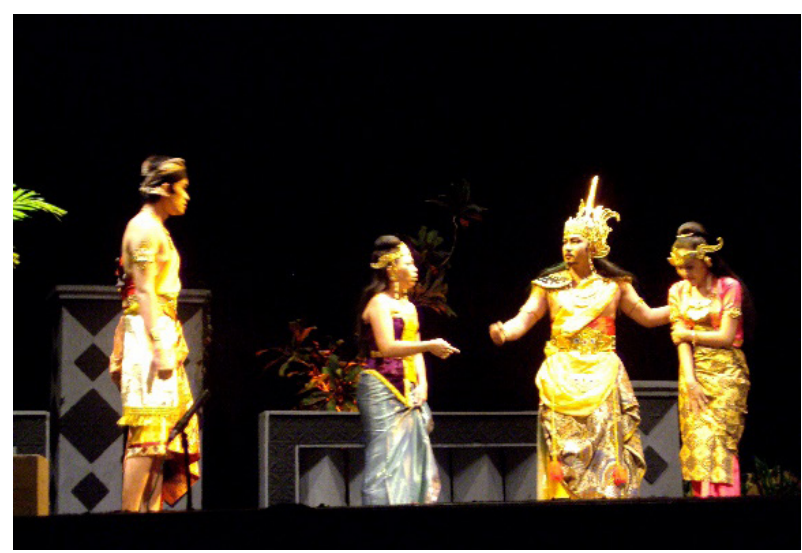

lagu-lagu yang tengah populer sehingga kelonggaran dramaturgi teater rakyat mendapatkan contoh yang nyata.

Ketoprak ringkes mencapai puncak tanggapan penonton ketika Pemerintah Daerah Yogyakarta menyatakan bahwa ketoprak adalah ikon pariwisata DIY. Pada hari Senin, 3 Desember 2007, Komunitas Tjonthong Djogdjakarta dan jajaran staf eksekutif dan legislatif Kota Yogyakarta menggelar sebuah ketoprak dengan lakon Nagih Janji Bumi Perdikan. Ketoprak dipentaskan di Taman Budaya Yogyakarta. Menurut koordinator pemain ketoprak, Sudibyo, hampir seluruh pimpinan Pemerintah Kota Yogyakarta terlibat dalam pertunjukan ini, misalnya: Wali Kota Yogyakarta, Herry Zudianto, sebagai abdi dalem bernama Kang Wagiman; Ketua DPRD Kota Yogyakarta, Arif Noor Hartanto, sebagai Sang Prabu Yudho Negoro; dan Kepala Kepolisian Kota Besar Yogyakarta, Komisaris Besar Agung Budi, sebagai Senopati Umbul Projo. Sejumlah seniman juga terlibat dalam pertunjukan ini, seperti Den Baguse Ngarso, Marwoto, Yuningsih Santoso, Helfi Dirix Affandi, dan Bagong Trisgunanto. Bahkan, kalangan ulama, seperti Ustadz Arif Al Fatah dan Sugeng Al Fatah, turut berpartisipasi dalam acara itu.

Pimpinan Produksi Ketoprak Ringkes, Bambang Paningron, mengemukakan ide pementasan ini muncul dari wali kota yang ingin melestarikan ketoprak sebagai ikon pariwisata seni budaya Yogyakarta. Penyusun naskah dan sutradara ketoprak,

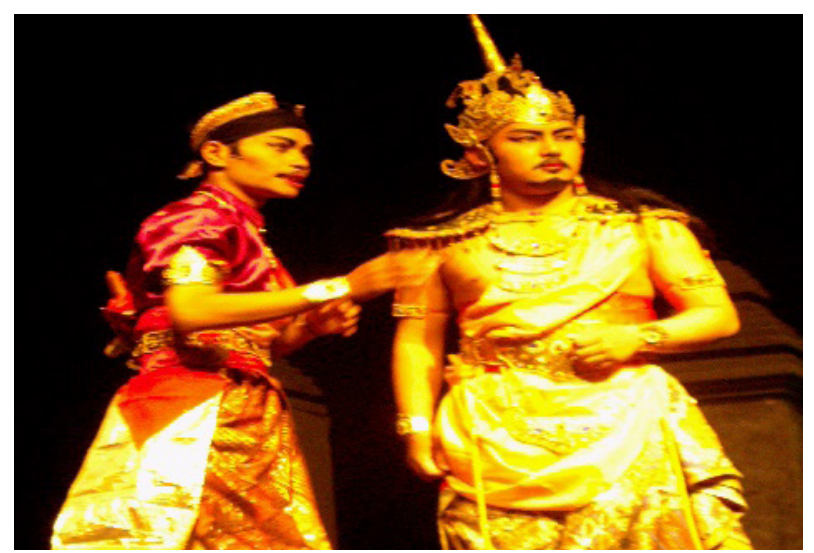

Gambar 7. Kamandaka Cinlok, Paguyuban Dimas Diajeng Yogyakart. Sutradara Ari Purnomo, Naskah Nano Asmorodono, 26 Juni 2009, Societet TBY. (Dokumentasi: Ninit) 
Nano Asmorodono, menuturkan lakon Nagih Janji Bumi Perdikan berkisah tentang perjuangan suatu daerah atas status khusus yang diberikan kerajaan. Daerah tersebut akan dibebaskan dalam segala urusan ketatanegaraan alias bersifat otonom. Lakon ini sekaligus melambangkan perjuangan rakyat DIY dalam mendapatkan status keistimewaan dengan disahkannya Rancangan Undang-Undang Keistimewaan yang hingga kini masih diproses di tingkat pemerintah pusat.

Beberapa ragam bahasa dalam ketoprak menunjukkan watak, kedudukan, trah keturunan, latar belakang, dan status sosial tokoh-tokoh yang tampil dalam setiap adegan. Dalam tradisi Jawa, tingkattingkat pemakaian bahasa tersebut berkait erat dengan unggah-ungguh, etika, tata krama, dan budi pekerti. Artikulasi dialog dalam berbahasa Jawa juga mempunyai arti penting dalam penyajian ketoprak sebagai tontonan karena pertunjukan ketoprak tanpa didukung artikulasi yang baik akan mengurangi nilai artistik dan estetika serta menghambat penyampaian makna dialog. Oleh karena itu, selain intonasi dan aksentuasi harus jelas, pemain ketoprak juga harus mampu mengucapkan dialog dengan benar dan lafal yang pas.

Unsur bahasa hanya menjadi salah satu faktor keadiluhungan kesenian ketoprak. Selain itu, unsur busana (kostum) juga mengandung ajaran watak dan kedudukan seseorang. Sejak kelahirannya, bahasa yang dipakai dalam pertunjukan ketoprak

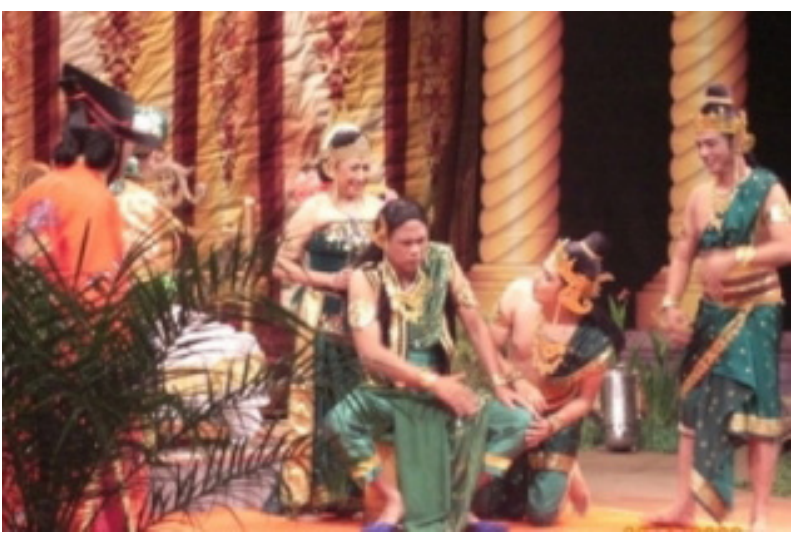

Gambar 8. Festival Ketoprak se-Provinsi DIY yang digelar mulai 17 hingga 19 Desember 2010 di Taman Budaya Yogyakarta.

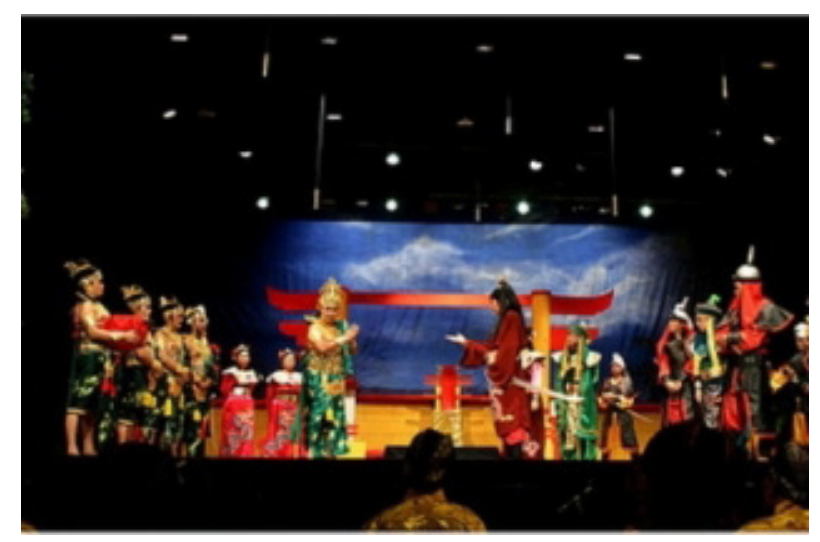

adalah bahasa Jawa. Sementara itu sistem komunikasi dalam ketoprak dilakukan dengan dialog dan tembang. Namun ragam bahasa yang digunakan dalam ketoprak lesung hanya bahasa ngoko atau krama ndesa, sedangkan dalam perkembangannya ketoprak menggunakan empat ragam bahasa. Ragam dalam ketoprak tersebut adalah krama inggil, krama ndesa, ngoko, kedhaton, dan bagongan. Hal itu seiring dengan perkembangan lakon-lakon ketoprak yang kemudian juga bersumber dari cerita sejarah dan babad, bukan hanya berasal dari legenda.

\section{Perkembangan Pertunjukan Ketoprak}

Dari uraian periodisasi ketoprak, tampak bahwa pertunjukan ketoprak berkembang secara dinamis. Terdapat upaya pembaruan untuk menyelaraskan perkembangan pertunjukan ketoprak dengan gejolak kehidupan masyarakat dan tuntunan zamannya. Salah satu penyebab adanya upaya pembaruan karena adanya perkembangan fungsi ketoprak, yaitu: sebagai pendidikan nilai-nilai bangsa dan sebagai hiburan bagi masyarakat. Dalam perkembangannya, ketoprak bersifat lentur, luwes, dan adaptif sehingga mudah sekali berbaur dengan dinamika masyarakat dan zamannya.

Pertunjukan ketoprak yang terselenggara selama sepuluh tahun (1999-2009) dapat diamati perkembangan bentuk pertunjukan ketoprak dengan tema-tema cerita yang ditampilkan. Demikian juga kelompok 
ketoprak yang pemainnya selalu hadir di hadapan penonton. Berdasarkan data yang terkumpul, jumlah kelompok, pertunjukan, dan seniman ketoprak di DIY sebagai berikut. 1. Jumlah kelompok ketoprak

a. Kabupaten Kulonprogo: 203 kelompok;

b. Kabupaten Gunung Kidul: 117 kelompok;

c. Kabupaten Bantul: 90 kelompok;

d. Kabupaten Sleman: 68 kelompok;

e. Kotamadya: 19 kelompok.

Jumlah keseluruhan kelompok ketoprak di DIY sebanyak 497 kelompok.

2. Jumlah Pertunjukan Ketoprak dari Tahun 1999-2009

a. Tahun 1999:10 kali;

b. Tahun 2000: 7 kali;

c. Tahun 2001: 3 kali;

d. Tahun 2002: 2 kali;

e. Tahun 2003; 5 kali;

f. Tahun 2004: 5 kali;

g. Tahun 2005: 15 kali;

h. Tahun 2006; 30 kali;

i. Tahun 2007: 21 kali;

j. Tahun 2008: 27 kali;

k. Tahun 2009: 20 kali.

Jumlah instansi yang menggunakan jasa kreatif seniman ketoprak di antaranya unsurunsur PEMDA Kabupaten-Kota dan Provinsi DIY, Perguruan Tinggi Negeri dan Swasta, sekolah umum, lembaga keagamaan, Lembaga Swadaya Masyarakat, perusahaan bisnis swasta dan pribadi. Sementara itu, unsur masyarakat yang pernah menjadi pemain ketoprak, di antaranya: pejabat negara seperti bupati, wali kota; rektor dan dekan Perguruan Tinggi, mahasiswa, karyawan, kepala sekolah, guru, dan siswa, pebisnis/pedagang, tokoh agama, tokoh masyarakat, ibu-ibu rumah tangga, waria, Putra-Putri Kecantikan DIY, anak-anak dan remaja. Selain itu, dukungan sponsor berasal dari Pemerintah Daerah dengan unsur-unsurnya: industri bisnis rokok, minuman kesehatan, Event Organiser, taman budaya, Perguruan Tinggi.

\section{Penutup}

Ketoprak sebagai kesenian tradisional mampu berkembang seiring perkembangan zaman dan teknologi karena ketoprak memang lentur, luwes dan adaptif. Bahkan ketoprak selalu terbuka terhadap pengaruh konsep seni dari luar ketoprak. Hal itu terlihat jelas dari sejarah perkembangan ketoprak yang terus berkembang dimulai dari ketoprak lesung, ketoprak ongkek, ketoprak pendapan, ketoprak panggung (tobong), ketoprak humor, dan ketoprak ringkes. Dalam kaitan teknologi komunikasi, ketoprak juga bisa beradaptasi dengan teknologi audio sehingga mulai 1937/1938, ketoprak sudah mengudara lewat radio (RRI). Tahun 1972, ketoprak tampil secara audio-visual lewat TVRI.

Jumlah kelompok ketoprak terbanyak berada di Kabupaten Kulonprogo, diikuti kemudian oleh Kabupaten Gunungkidul, Kabupaten Bantul, Kabupaten Sleman, dan terakhir Kotamadya. Meskipun ada beberapa ketoprak yang sudah tidak ada, namun anggotanya membentuk kelompok ketoprak baru. Hal tersebut menunjukkan bahwa ketoprak masih diinginkan hadir oleh masyarakat, terutama menjelang hari-hari besar kenegaraan, seperti HUT RI, ulang tahun kabupaten, hari besar keagamaan, dan festival antar kabupaten dan kecamatan.

Jumlah pertunjukan ketoprak mengalami perkembangan dari tahun 1999 hingga 2009. Tahun 1999 hingga tahun 2004 tercatat hanya sekitar 32 kali pertunjukan dibandingkan dengan 113 kali pertunjukan di tahun 2005 hingga tahun 2009. Tahun 1970-an merupakan tahun keemasan bagi pertunjukan dan seniman ketoprak. Fenomena itu bermula tahun 1990-an ketika terjadi loncatan teknologi informasi dan industrialisasi. Sekitar lima puluh kelompok ketoprak tumbuh subur di Yogyakarta. Oleh karena diminati publik, mereka pentas tobong (berkeliling) dari kampung ke kampung. Situasi itu didukung oleh TVRI yang memberi ruang yang longgar bagi kesenian rakyat. Tayangan ketoprak di TVRI Yogyakarta bersinergi dengan maraknya pertunjukan ketoprak di panggung-panggung rakyat. Tayangan "Ketoprak Sayembara" di TVRI Yogyakarta pada tahun 1994-1995 yang berdurasi sekitar 50 menit itu masih mampu menerima 800 ribu kartu pos dari pemirsa. 
Tahun 2000-2004, kondisi ketoprak mengalami kemunduran. Penggemar ketoprak di televisi menyusut. Bondan mengutip sebuah riset dari kelompok studi Realino mengenai tanggapan pemirsa terhadap penonton ketoprak. Dua tahun terakhir, kartu pos yang masuk menyusut tajam menjadi 26 ribu. Jika rata-rata penonton mengirim empat kartu, berarti peminat ketoprak tinggal 6.500 orang penggemar. Pertunjukan ketoprak di panggung pun menyusut. Tidak sepenuhnya televisi sebagai biang utama kepunahan seni tradisi. Kesalahan utama terletak pada kegagapan pekerja seni. Mereka gagap dan tidak kreatif menarik kembali hasrat publik yang hilang. Pekerja seni tradisi tidak siap menghadapi tantangan zaman sehingga minat publik beralih ke tayangan yang estetikanya lebih menarik.

Tahun 2005 merupakan tonggak perkembangan ketoprak. Kondisi tersebut dipicu oleh faktor-faktor sebagai berikut, Pertama, kesadaran pemerintah daerah untuk menentukan ikon pariwisata DIY sebagai bagian dari globalisasi. Kedua, kesadaran seniman untuk mengemas pertunjukan yang menyesuaikan tuntutan jaman dengan format baru dan segar meliputi alur cerita ringkes, memasukan unsur teater, tari dan lagu tema pertunjukan. Ketiga, kesadaran akan mahalnya produksi ketoprak sehingga strategi pengemasan tata artistik simbolis dan didukung trik-trik ketoprak tobong. Keempat, pengaruh ketoprak humor dan ketoprak ringkes yang tetap menggunakan gaya plesetan dan banyolan menyebabkan pertunjukan ketoprak bukan lagi alat politik semata, tetapi alat dan tempat bersilaturahim warga masyarakat. Kelima, cerita tidak lagi berdasarkan mitos, babad dan legenda, tetapi merambah cerita pewayangan namun dengan penafsiran cerita yang lebih kontekstual dengan masa kini. Keberhasilan pembaruan pertunjukan ketoprak dapat dilihat dengan banyaknya pertunjukan yaitu 113 kali selama 5 tahun (dari tahun 2005 hingga 2009), yang berarti setiap tahun ada dua puluh kali pertunjukan ketoprak, dan setiap bulan ada dua kali pertunjukan ketoprak.
Pemain ketoprak pun yang sebelum tahun 2000-an berasal dari kalangan bawah-disiang hari para pemain sering menjadi pemulung, tukang parkir, tukang becak, dan kalangan seniman tradisional ketoprak, berkembang ke lingkungan menengah ke atas dan dari berbagai kalangan profesi. Dari tingkat bupati/ wali kota, rektor, dosen, mahasiswa, hingga karyawan kebersihan di instansi pemerintahan terlibat semua dalam pertunjukan ketoprak. Para pejabat terkadang minta diberi peran dan rela tidak dibayar. Bahkan mereka sering membayar melalui bentuk sponsorship demi keberhasilan produksi pertunjukan ketoprak. Kaum perempuan juga tidak ketinggalan berpartisipasi mengembangkan ketoprak dengan mendirikan kelompok ketoprak yang dipimpin oleh perempuan. Anak-anak pun tidak ketinggalan bermain dalam pertunjukan ketoprak.

Dengan melihat banyaknya kegiatan pertunjukan ketoprak di DIY, tidak salah jika ketoprak telah menjadi ikon budaya dan pariwisata di DIY. Pertunjukan ketoprak yang berlangsung hampir setiap bulan dengan jumlah partisipasi masyarakat, baik sebagai seniman maupun penonton ketoprak, yang setiap tahun meningkat menyebabkan ketoprak mampu menjadi representasi kegiatan kesenian milik Yogyakarta. Pertunjukan ketoprak menapaki keberlangsungannya bukan lagi sebagai kesenian tradisional, tetapi sudah menjadi bentuk kesenian modern.

Pemerintah Daerah DIY harus mempertahankan dan meningkatkan kondisi tersebut dikarenakan oleh kecenderungan adanya saat-saat tertentu produk kreatif yang terkait dengan industri akan mengalami titik kejenuhan. Kewaspadaan seniman dan penonton terhadap keberadaan pertunjukan ketoprak harus ditingkatkan dengan cara meningkatkan peran pemerintah sebagai pelindung seni dan budaya. Pemerintah mencari terus strategi-strategi perawatan dan perlindungan ketoprak. Kerjasama dengan perguruan tinggi, pencarian dana perusahaan untuk mensponsori ketoprak, kerjasama dengan seniman ketoprak, 
gencarnya promosi pertunjukan ketoprak, penyelenggaraan festival dan lomba ketoprak harus terselenggara secara kontinyu. Upaya meningkatkan kualitas ketrampilan seniman ketoprak oleh PEMDA terus diasah. Tentu saja silaturahim antarseniman ketoprak harus terus digalakkan melalui pertemuan ajang kreativitas seniman. Pemerintah Daerah juga memberi penghargaan seni dan budaya terhadap seniman ketoprak atas pengabdian dan jasa-jasa mereka.

\section{Kepustakaan}

Barthes, Roland. 1981. "Theory of the Text", dalam Robert Young, ed. Unitying the Text. A Post Structuralist Reader, London and New York: Routledge.

Dananjaya, James, 1983.“Fungsi Teater Rakyat Bagi Kehidupan Masyarakat Indonesia. (Ketoprak/Dagelan Siswo Budoyo Sebagai Suatu Kasus Studi)", dalam Edi Sedyawati. Sapardi Djoko Damono, ed. Seni Dalam Masyarakat Indonesia. Bunga Rampai, Jakarta: PT Gramedia Pustaka Utama.

De Marinis, Marco. 1993. The Semiotics of Performance. Terj. Aine O'Heady,
Bloomington and Indianapolis: Indiana University Press

Hirsch, Jr., E. D. 1967.Validity in Interpretation, New Haven and London: Yale University Press.

Jabrohim (ed.), 2003. Metodologi Penelitian Sastra, Yogyakarta: Hanindita Graha Widya, 2003. Jauss, Hans Kuntowijoyo, Metodologi Sejarah, Yogyakarta: PT Tiara Wacana Yogya.

Kussudyarsana, Handung. 1989. Ketoprak, Yogyakarta: Penerbit Kanisius.

Muhajir, Noeng. 2000. Metodologi Penelitian Kualitatif, Yogyakarta: Rake Sarasin,

Pavis, Patrice. 1992. Theatre at the Crossroads of Culture, New York: Routledge, London,

Rendra, 1984. Mempertimbangkan Tradisi, Jakarta: PT Gramedia.

Soedarsono, 2001. Metodologi Penelitian Seni Pertunjukan dan Seni Rupa, Bandung: MSPI \& arti.line.

Sweeney, Amin. 1987. A Full Hearing. Orality and Literacy in the Malay world, London: University of California Press, Ltd.

Vansina, Jan. 1985. Oral Tradition as History, Wisconsin: The University of Wisconsin Press. 


\section{SUBJECT INDEX}

\section{A}

acculturation 25, 26, 34

arts of Gresik district 32

B

Bambang Dharmojati $42,43,45,46,50$

C

character education 17

corporeality 53,57

creativity $1,13,94$

D

dramaturgy $74,82,83$

E

ecocriticism 53

ethnographic approach 64

explanation method 64

F

form and structure 64

formal and non-formal education 17

G

globalization 94

I

identity $36,63,84,94$

Indang tradisi $64,66,68,69,70,72,73$

Islamic nuances 25

Islamic-Javanese culture 25

$\mathbf{K}$

Ketoprak 25, 26, 27, 28, 29, 30, 31, 32, 33, $34,94,95,96,97,98,99,100,101,102$, $103,104,105$

kuda kepang $1,2,3,4,5,6,7,8,9,10,11,12$, $13,14,15,16$
$\mathbf{L}$

local wisdom values 35

M

markets 1

multiple transformations 1

$\mathbf{0}$

Opera Batak $74,75,76,77,78,79,80,81$, 82,83

$\mathbf{P}$

pantomime 17,20

performance $14,25,42,53,61,63,66,74$, 94,105

performative value 53

R

revitalization 84,93

S

Sanggar Sri Palembang $\quad 42,43,45,46,47$, $48,49,50$

Sasaran 35, 36, 37, 38, 39, 40,

Sasaran Style of Galombang dance 35

society $34,42,64,74$

strengthening 94

T

Tayung Raci dance 84

the Egyptian style 25

the professionalism of educators 17

theatre $74,75,83$

traditions 1

W

Wayang Palembang $\quad$ 94, 95, 96, 97, 98, 99, $100,101,102$ 


\section{AUTHOR INDEX}

Fadilla, Aminatul 42

Fitriasari, Rr. Paramitha Dyah

1

Haryono, Timbul 1

Indrayuda 64

Iswantara, Nur 17

Kiswanto 1

Mufrihah, Dwi Zahrotul 84

Nerosti 35

Nurcahyono, Wahid
Purba, Silvia Anggreni 94

Saddhono, Kundharu 25

Sahid, Nur 74

Setyawan, Bagus Wahyu 25

Siagian, Lismade Soraya Juliana $\quad 74$

Sunaryo 17

Susmiarti 64

Wibono, Catur 74

Widaryanto, F. X. 53

Yudiaryani 94 